\title{
Emprego do óleo de Melaleuca alternifolia Cheel (Myrtaceae) na odontologia: perspectivas quanto à utilização como antimicrobiano alternativo às doenças infecciosas de origem bucal
}

\author{
OLIVEIRA, A.C.M. '; FONTANA, A. ${ }^{2}$; NEGRINI, T.C. ${ }^{2}$; NOGUEIRA, M.N.M.'; BEDRAN, T.B.L. ${ }^{2}$; ANDRADE, C.R. ${ }^{2}$; \\ SPOLIDORIO, L.C. ${ }^{2}$; SPOLIDORIO, D.M.P. ${ }^{2 *}$ \\ ${ }^{1}$ Faculdade de Odontologia de Piracicaba, Unicamp, Avenida Limeira, 901, CEP: 13414-903, Piracicaba-Brasil \\ ${ }^{2}$ Faculdade de Odontologia de Araraquara, Unesp, Rua Humaitá, 1680, CEP: 14801-903, Araraquara-Brasil \\ *dmps@foar.unesp.br
}

\begin{abstract}
RESUMO: O interesse por medicamentos alternativos, principalmente daqueles provenientes de extratos naturais, tem aumentado nas últimas décadas. A Melaleuca alternifolia é um arbusto pertencente ao gênero Melaleuca, popularmente conhecida como "árvore de chá", cujo principal produto é o óleo essencial (TTO - tea tree oil), de grande importância medicinal por possuir comprovada ação bactericida e antifúngica contra diversos patógenos humanos. Em virtude da atividade terapêutica em diversas especialidades médicas, o TTO passou a ser empregado na área odontológica. Esta revisão de literatura foi realizada com o objetivo de discutir os ensaios já realizados com o TTO contra microrganismos relacionados à doença cárie, doença periodontal e problemas pulpares. O óleo de Melaleuca tem demonstrado boa ação antibacteriana in vitro contra microrganismos bucais, porém, pesquisas envolvendo o estudo do mecanismo de ação sobre as células microbianas ou estudos in vivo ainda são escassos e precisam ser realizados, já que esse produto pode ser útil na odontologia, seja na manutenção química da higiene ou prevenção de doenças bucais.
\end{abstract}

Palavras-chave: Melaleuca alternifolia, óleo da árvore de chá, agentes antimicrobianos, odontologia

\begin{abstract}
Use of Melaleuca alternifolia Cheel (Myrtaceae) oil in dentistry: perspectives on its use as alternative antimicrobial to infectious diseases of oral origin. The interest in alternative medicines, especially those from natural extracts, has increased in recent decades. Melaleuca alternifolia is a shrub belonging to the genus Melaleuca, popularly known as "tea tree", the main product of which is its essential oil (TTO - tea tree oil), of great medicinal importance for its proven bactericidal and antifungal activity against several human pathogens. By virtue of its therapeutic activity in various medical specialties, TTO is now used in dentistry. This literature review was conducted in order to discuss the tests already carried out with TTO against microorganisms related to dental caries, periodontal disease and pulpal problems. Melaleuca oil has shown good in vitro antibacterial activity against oral microorganisms; however, research involving the study of its mechanism of action on the microbial cells or in vivo studies are still scarce and need to be done since this product may be useful in dentistry, either in the chemical maintenance of hygiene or in the prevention of oral diseases.
\end{abstract}

Key words: Melaleuca alternifolia, tea tree oil, antimicrobial agents, dentistry

O conhecimento popular tem trazido grande contribuição para divulgação do uso de plantas no tratamento de doenças. Nas últimas décadas tem aumentado o interesse por medicamentos alternativos, na maior parte deles proveniente de extratos naturais, desencadeando busca pela validação do uso desses medicamentos, visto os efeitos terapêuticos favoráveis in vitro e in vivo (Carson et al., 2006).

A medicina popular desperta o interesse de pesquisadores em estudos multidisciplinares que enriquecem o conhecimento a respeito do uso terapêutico de plantas medicinais (Maciel et al., 2002).

Recebido para publicação em 30/06/2009

Aceito para publicação em 26/07/2010

Rev. Bras. PI. Med., Botucatu, v.13, n.4, p.492-499, 2011. 
De acordo com a OMS (Organização Mundial da Saúde), aproximadamente $80 \%$ da população mundial utilizam a medicina alternativa, principalmente medicamentos fitoterápicos, para suprir a ausência de atendimento médico primário (Elizabetsky, 1997). $\mathrm{Na}$ África, por exemplo, $80 \%$ da população dependem do uso destes medicamentos, os quais representam terapias alternativas frente ao alto custo dos fármacos sintéticos (Aschwanden, 2001).

Medicamentos de origem vegetal também são populares em países desenvolvidos. Estima-se que $50 \%$ dos canadenses e $75 \%$ dos franceses utilizam fitoterápicos (Aschwanden, 2001). Na Alemanha no ano de 1997, se consumia metade dos extratos vegetais comercializados em toda a Europa (cerca de US\$ 3,5 bilhões do total de US\$ 7 bilhões, ou US\$42,90 per capita). Para a população alemã em 1997, as plantas medicinais eram utilizadas para tratar resfriados (66\%), gripe (38\%), doenças do trato digestivo ou intestinal (25\%), dores de cabeça (25\%), insônia (25\%), úlcera estomacal (36\%), nervosismo (21\%), bronquite (15\%), doenças de pele (15\%), fadiga e exaustão (12\%). Nesse mesmo país, foi verificado que a automedicação com preparações à base de plantas medicinais era muito comum (Calixto, 2000).

O gênero Melaleuca, pertencente à família Myrtaceae, inclui aproximadamente 100 espécies nativas da Austrália e Ilhas do Oceano Índico. Melaleuca alternifolia é comumente conhecida na Austrália como "árvore de chá", florescendo principalmente em áreas de pântano, próximas de rios. O principal produto é o óleo essencial (TTO - tea tree oil), de grande importância medicinal por possuir comprovada ação bactericida e antifúngica contra diversos patógenos humanos, sendo utilizado em formulações tópicas. É extraído da planta por hidrodestilação ou destilação por arraste a vapor (Gustafson et al., 1998; Carson et al., 2006).

Melaleuca alternifolia passou a ser conhecida no ocidente a partir de 1770 quando a expedição do capitão James Cook aportou na baía de Botany na Austrália e observou nativos fazendo uso de chá de folhas de árvore com propriedades medicinais. Durante a Segunda Guerra Mundial, soldados australianos tinham como parte dos kits militares, o óleo de melaleuca para o tratamento de feridas (Hammer et al., 2002) com utilização tópica (Altman, 1989; Syed et al.,1999).

É também na Austrália onde se concentram os principais produtores dessa espécie, que dominam o mercado e as tecnologias de produção. A comercialização dos produtos à base de TTO surgiu na década de 20, após descrição das propriedades medicinais (Penfold \& Grant, 1923, 1924, 1925). Foi a partir das décadas de 70 e 80 que se iniciaram em grande escala as plantações da Melaleuca alternifolia, permitindo às indústrias comercializarem os produtos à base de TTO (Brophy et al., 1989; Johns et al., 1992). Estudos iniciais sobre a atividade antimicrobiana de Melaleuca alternifolia foram descritos na literatura ocidental a partir de 1962 por Peña a partir de investigações com Tricomonas vaginalis.

Atualmente, o TTO é empregado como agente antimicrobiano ou preventivo em escala farmacêutica ou cosmética e a indicação vai desde a utilização em lesões, queimaduras, picadas de inseto, gel para espinhas, cremes vaginais, cremes para a pele até dentifrícios (Cox et al., 2001). Em virtude da boa ação antimicrobiana e do amplo emprego em diversas especialidades médicas, o TTO passou a ser empregado também na área odontológica.

Esta revisão de literatura foi realizada com o objetivo de entender o mecanismo de ação do TTO em relação a diferentes problemas bucais e sua eficácia no tratamento e prevenção da cárie, doença periodontal e problemas pulpares.

\section{Composição e características químicas}

O TTO possui aproximadamente 100 componentes (Brophy et al., 1989), sendo os principais (Tabela 1) (Carson et al., 2006) o terpinen4-ol, gama-terpieno, $\alpha$-terpieno, 1,8 cineol e $\alpha$-pineno (Cox et al., 2001) e é um óleo parcialmente solúvel em água. Para se obter solução aquosa do óleo, é necessário adicionar agentes emulsificantes, tais como Tween 20 ou Tween 80 , os quais não alteram as propriedades antimicrobianas (Willians, 1990). De acordo com o comitê australiano, para que o TTO possua atividade antisséptica, ele deve conter quantidade de cineol abaixo de $15 \%$ e de terpinen-4ol acima de $30 \%$ (International Organisation for Standardisation, 2004).

O Terpinen-4-ol está presente em 30-40\% da composição (Carson et al., 2006), sendo o componente que detêm a principal atividade antimicrobiana, pois induz perda da membrana, interferindo na integridade e fisiologia bacteriana.

O 1,8-cienole, considerado irritante da pele, pode aumentar a permeabilidade da membrana facilitando a entrada de outros agentes antimicrobianos e por isso alguns autores o consideram como detentor de efeito antimicrobiano marginal (Willians, 1990; Carson et al., 2002; Groppo, 2002; Hammer et al., 2003).

O TTO é considerado um óleo com boas propriedades de penetração nos tecidos (Altman, 1989). A composição pode sofrer influências de vários fatores, dentre eles o tempo de armazenamento, presença de luz, calor, exposição ao ar e umidade, os quais podem afetar a estabilidade do óleo. Portanto, ele deve ser armazenado preferencialmente no escuro, sob baixa temperatura, sem umidade e com pouca quantidade de ar (Carson et al., 2006). 
TABELA 1. Principais componentes do óleo de Melaleuca e as proporções (Carson et al., 2006).

\begin{tabular}{ccc}
\hline & \multicolumn{2}{c}{ Composição (\%) } \\
\cline { 2 - 3 } Componente & ISO $4730^{a}$ & Composição típica \\
\hline Terpinen-4-ol & $=30^{b}$ & 40,1 \\
$\gamma$-Terpineno & $10-28$ & 23,0 \\
$\alpha$-Terpineno & $5-13$ & 10,4 \\
1,8 -Cineole & $=15^{c}$ & 5,1 \\
Terpinoleno & $1,5-5$ & 3,1 \\
$\rho$-Cymene & $0,5-12$ & 2,9 \\
$\alpha$-Pinene & $1-6$ & 2,6 \\
$\alpha$-Terpineol & $1,5-8$ & 2,4 \\
Aromadendrene & Mínimo-7 & 1,5 \\
$\delta$-Cadinene & Mínimo-8 & 1,3 \\
Limoneno & $0,5-4$ & 1,0 \\
Sabineno & Mínimo-3,5 & 0,2 \\
Globulol & Mínimo-3 & 0,2 \\
Viridiflorol & Mínimo-1,5 & 0,1 \\
\hline
\end{tabular}

${ }^{a}$ ISO 4730, Organização Internacional para Padronização. ${ }^{b}$ Nenhum limite superior está definido, embora $48 \%$ sejam propostos. ${ }^{c}$ Nenhum limite inferior está definido.

\section{Mecanismo de ação do TTO}

Dados recentes mostram que o TTO possui amplo espectro de ação antibacteriana, possuindo efeito bactericida in natura e bacteriostático em baixas concentrações (Wilkinson \& Cavanagh, 2005; Kwiecinski et al., 2008; Van Vuuren et al., 2009), antifúngico (Oliva et al., 2003; Trabulsi et al., 2008) e antiviral (Minami et al., 2003).

O mecanismo de ação bactericida consiste no comprometimento da integridade da membrana celular, consequente perda de material intracelular, incapacidade de manter a homeostase e inibição da respiração (Carson et al., 2006). Contudo, por possuir cerca de 100 componentes, existe a possibilidade de não ter sido pesquisado todo o potencial de atuação. É possível que outros elementos, ainda não avaliados, contribuam para a atividade antimicrobiana com mecanismo de ação diferente daquele já encontrado (Hammer et al., 2003).

Cox et al. (2000) observaram a eficácia do TTO para E. coli, S. aureus e C. albicans e confirmaram que a atividade antimicrobiana se deve à capacidade de romper a barreira de permeabilidade da membrana dos microrganismos, inibindo a respiração. Este modo de ação é similar a outras substâncias desinfetantes que têm ação sobre a membrana dos microrganismos como os derivados do fenol, a clorexidina e derivados do ácido parabenzóico. Jandourek et al. (1998) verificaram a eficácia de soluções orais de TTO no tratamento da candidíase resistente ao tratamento com fluconazol em pacientes aidéticos, demonstrando aparente efetividade.
Devido à ação bactericida, evidências científicas sugerem que o TTO possa ser útil na manutenção química da higiene bucal e na prevenção de doenças dentais (Jandourek et al., 1998; Hammer et al., 2002; Groppo et al., 2002; Hammer et al., 2003; Filoche et al., 2005).

\section{Ação do TTO em microrganismos cariogênicos}

A cárie dental continua sendo considerada uma das infecções bucais mais comuns, apesar dos avanços na redução de sua prevalência (Bowen, 2002). É uma doença causada pela interação de vários fatores, relacionados aos microrganismos, como suscetibilidade do hospedeiro, dieta e tempo (Selwitz et al., 2007). Os microrganismos presentes no biofilme são considerados um dos fatores de maior importância para o início e progressão da doença (Farsi, 2008). O biofilme dentário é formado por comunidade de microrganismos que se aderem à superfície dental organizando-se funcionalmente no interior da matriz extracelular (Mah, 2001; Spratt \& Pratten, 2003) e são capazes de modificar o ambiente para favorecer o crescimento e a sobrevivência (Davey \& O'Toole, 2000).

Os estreptococos do grupo mutans (particularmente Streptococcus mutans) e os Lactobacillus spp. são bactérias Gram-positivas com alto potencial cariogênico. O freqüente consumo de carboidratos fermentáveis pode levar a constantes quedas de $\mathrm{pH}$ no biofilme gerando aumento nas proporções de espécies sacarolíticas acidúricas e acidogênicas como os estreptococos do grupo

Rev. Bras. PI. Med., Botucatu, v.13, n.4, p.492-499, 2011. 
mutans e lactobacilos. O aumento na proporção dessas espécies leva à produção cada vez maior de ácido, promovendo a desmineralização do dente e deixando a superfície dental mais susceptível ao aparecimento de lesões de cárie (De Lorenzo \& De Lorenzo, 2004).

Por conta disso, muitas substâncias são usadas com a finalidade de reduzir o número de bactérias que colonizam a cavidade oral. O uso de flúor é o método quimioterápico mais eficaz no controle da doença dental, pois essa substância possui ação antibacteriana e capacidade de remineralizar lesões de cárie incipiente. Porém, a exposição prolongada a altas concentrações de flúor durante o período de desenvolvimento dentário pode levar à fluorose dental, a qual é considerada distúrbio ou defeito de formação do esmalte (Villena \& Cury, 1998).

A clorexidina é aceita como padrão-ouro para o tratamento de doenças bucais. Geralmente é mais eficaz contra microrganismos Gram-positivos, incluindo os estreptococos do grupo mutans, que são particularmente sensíveis à clorexidina. Porém, a frequente utilização de clorexidina não é aconselhável devido aos efeitos colaterais locais, como a descoloração de dentes, restaurações e próteses, ulceração da mucosa oral e alteração da percepção gustativa (Twetman, 2004; Paraskevas, 2005; Gunsolley et al., 2006; Ditterich et al., 2007).

Devido à ação bactericida, evidências científicas sugerem que o TTO possa ser útil na manutenção química da higiene e prevenção de doenças bucais (Hammer et al., 2003). Kulik et al. (2000) avaliaram a atividade bacteriostática e bactericida/fungicida in vitro da solução de TTO em diferentes microrganismos bucais, concluindo que $A$. actinomycetemcomitans, $F$. nucleatum e $P$. gingivalis foram os microrganismos mais suscetíveis, enquanto o $S$. mutans e $P$. intermedia foram menos sensíveis ao óleo de Melaleuca.

Para verificar a eficácia do óleo de Melaleuca como alternativa para a substituição do uso da clorexidina, Groppo et al. (2002) avaliaram o número de microrganismos bucais totais e $S$. mutans demonstrando alta atividade antimicrobiana para Streptococcus mutans, mas não para outros microrganismos e que esta solução apresenta efeito residual nas duas semanas pós-tratamento, diferentemente da clorexidina.

Para avaliar a susceptibilidade in vitro do óleo de Melaleuca, Hammer et al. (2003) avaliaram isolados de bactérias bucais, verificando redução de $10^{3} \mathrm{UFC} \mathrm{\textrm {mL } ^ { - 1 }}$ após 30 segundos e após 5 minutos não foram detectados microrganismos viáveis. Os autores sugeriram que o TTO poderia ser utilizado em produtos de manutenção da saúde bucal devido à atividade sobre diferentes microrganismos.

Filoche et al. (2005) compararam os efeitos antimicrobianos de diversos óleos essenciais, incluindo o óleo de Melaleuca, isolado e em combinação com a clorexidina em formas planctônicas ou biofilme de $S$. mutanse L. plantarum, concluindo que a combinação da clorexidina com os óleos essenciais apresentou melhores resultados em biofilme quando comparados à cultura planctônica.

Ditterich et al. (2007) avaliaram in vitro a ação antimicrobiana de sete dentifrícios que apresentavam na composição substâncias naturais, estando presente em um deles o extrato de Melaleuca. Este dentifrício especificamente teve ação contra $S$. aureus e E. coli, porém, os microrganismos na amostra de saliva total mostraram-se mais resistentes à atuação.

A redução do número de bactérias que colonizam a cavidade bucal contribui para o controle e prevenção da cárie. Através dos estudos apresentados, o TTO mostra ser fitoterápico de grande ação antibacteriana, podendo ser alternativa para o controle de microrganismos cariogênicos.

\section{Ação do TTO sobre microrganismos periodontais}

A remoção mecânica do biofilme dentário é o método mais utilizado na prevenção das doenças periodontais. A adição de antimicrobianos, seja no creme dental ou nas soluções para bochecho, tem a função de complementar o controle mecânico e a atuação é percebida nos pacientes com nível de escovação insatisfatório. A clorexidina, o triclosan, o cloreto de cetilpiridíneo e os óleos essenciais são agentes químicos que possuem ação comprovada no combate à formação do biofilme dentário e consequente inflamação gengival (Groppo et al., 2002; Gunsolley, 2006; Ditterich et al., 2007).

Nesse contexto, o TTO pode ser considerado como opção para o tratamento das doenças periodontais. Ao contrário da clorexidina, esse óleo não mancha os dentes e a ação antimicrobiana é somada ao efeito antiinflamatório. Os antissépticos atuais diminuem o biofilme dentário, com isso, reduzem o quadro inflamatório do periodonto (Hammer et al., 2003; Groppo et al., 2002). Muitos estudos demonstram que a atividade antinflamatória do TTO se deve à porção solúvel (terpinen-4-ol, $\alpha$-terpineol e 1,8-cineol). Hart et al. (2000) relataram redução em cerca de 40 a $50 \%$ na produção de interleucina $1 \beta$ (IL-1 $\beta$ ), fator de necrose tumoral á (TNFá), interleucina 10 (IL-10) e prostaglandina $\mathrm{E}_{2}$ após 40h, principalmente utilizando terpinen-4-ol, $\alpha$-terpineol e 1,8-cineol.

Arweiler et al. (2000) procuraram avaliar a ação do bochecho de TTO a 0,34\% no crescimento e viabilidade do biofilme supragengival comparando-o ao bochecho com clorexidina a $0,1 \%$ e placebo. $A$ clorexidina demonstrou maior redução do acúmulo de biofilme dentário quando comparado ao placebo, enquanto que o TTO comparado ao placebo não

Rev. Bras. PI. Med., Botucatu, v.13, n.4, p.492-499, 2011. 
demonstrou ação sobre o crescimento do biofilme supragengival. Quanto à viabilidade do biofilme, os autores encontraram diminuição tanto para TTO quanto para a clorexidina, porém nesta última a diferença foi significativa.

Para avaliar in vitro a suscetibilidade dos microrganismos Aggregatibacter actinomycetemcomitans e Prevotella intermedia ao TTO, Hammer et al. (2003) observaram que o TTO a 0,5\% elimina as bactérias em 30 segundoseque concentrações inferiores possuem ação bacteriostática. Os autores salientaram que esse efeito não pode ser diretamente refletido para estudos in vivo, uma vez que pesquisas testando outros antibacterianos com bons resultados in vitro não demonstraram o mesmo desempenho in vivo, concluindo que há necessidade de mais trabalhos in vivo para determinar a concentração de TTO eficaz.

Nessa mesma linha de pesquisa, Takarada et al. (2004) testaram o efeito antibacteriano do TTO sobre o biofilme dentário e a ação in vitro para $A$. actinomycetemcomitans, Fusobacterium nucleatume Porphyromonas gingivalis, concluindo que o TTO suprime a formação do biofilme dentário in vitroe possui ação bactericida.

Soukoulis \& Hirsch (2004) investigaram o efeito do TTO na formação do biofilme dentário e inflamação gengival pré-existente. Para tanto, avaliaram indivíduos com gengivite durante 8 semanas, os quais foram divididos em 3 grupos, o gel de TTO a 2,5\%, gel clorexidina a $0,2 \%$ e placebo. Os resultados demonstraram a ação antiinflamatória do TTO, onde foi observada diminuição do Índice gengival e do Índice de sangramento papilar. Entretanto a ação contra o acúmulo de biofilme dentário apresentou-se menor quando comparado à clorexidina.

Portanto, observa-se que o TTO possui boa ação antimicrobiana in vitro sobre microrganismos bucais, porém, são escassas as evidências clínicas da ação do TTO para uso em Periodontia. A eficácia contra formação e acúmulo do biofilme dentário e tratamento das alterações periodontais é tema pouco explorado (Arweiler et al., 2000; Groppo et al., 2002; Soukoulis \& Hirsch, 2004; Carson et al., 2006), as pesquisas existentes apresentam resultados diversificados não permitindo comparação, uma vez que o veículo de solubilização do TTO, protocolos e objetivos foram distintos nos diferentes trabalhos. Assim, torna-se necessário a execução de estudos clínicos para que se possa verificar a atuação do TTO na prevenção e tratamento das doenças periodontais.

\section{Ação do TTO sobre microrganismos endodônticos}

O sucesso do tratamento endodôntico depende da correta execução de todas as fases operatórias (Leonardo, 2005). A permanência de microrganismos nos túbulos dentinários e ramificações do canal principal após o preparo biomecânico e a infiltração pode ser evitada através da utilização de medicação intra-canal e preenchimento hermético do canal radicular.

Mesmo depois de adequado preparo biomecânico sob abundante irrigação com soluções antissépticas, alguns microrganismos podem permanecer no interior do sistema de canais radiculares levando à manutenção da patologia endodôntica. Os microrganismos mais comumente encontrados em casos de insucesso do tratamento endodôntico são leveduras como Candida albicans altamente resistente ao preparo biomecânico e à medicação intracanal (Valera et al., 2001) e bactérias anaeróbias facultativas Gram-positivas como Enterococcus faecalis o qual possui capacidade de sobrevivência no sistema de canais radiculares durante e após o tratamento endodôntico (Hachmeister et al., 2002; Mangin et al., 2003; Shipper et al., 2004; Sedgley et al., 2005; Baumgartner et al., 2007).

Como tentativa de inibir a sobrevivência desses microrganismos, a utilização do hidróxido de cálcio é difundida como medicação intra-canal (Leonardo, 2005), assim como outras substâncias, dentre elas o PMCC (Paramonoclorofenol Canforado), gel de clorexidina $2 \%$ e o hipoclorito de sódio 1\% (Delany et al., 1982; Barbosa et al., 1997; Fachin et al., 2006). $\mathrm{Na}$ tentativa de encontrar outras substâncias que possuam propriedades antimicrobianas capazes de inativar os microrganismos causadores das patologias pulpares, pesquisadores têm tentando desenvolver alternativas às soluções irrigadoras e curativos de demora atualmente utilizados.

Sadr Lahijani et al. (2006), testaram a ação do $\mathrm{NaOCl}$ (Hipoclorito de sódio) associado ou não ao EDTA $17 \%$, extrato de camomila, TTO $2.5 \%$ e água destilada como irrigante intra-canal na remoção da smear layere não encontraram diferença estatística significante entre os grupos de água destilada, TTO $2.5 \%$ e NaOCl. Os autores concluíram que a remoção efetiva da smear layer ocorreu após utilização do $\mathrm{NaOCl}$ associado ao EDTA $17 \%$ (grupo controle) seguido do extrato de camomila. OTTO não foi capaz de limpar eficientemente as paredes dos canais radiculares devido à alta tensão superficial.

A literatura tem demonstrado a eficácia do TTO sobre variadas espécies de fungos, dentre eles a Candida albicans. Hammer et al. (2002) relataram a atividade do TTO em fungos filamentosos, onde o mesmo demonstrou atividade fungiostática e fungicida. $\mathrm{O}$ tratamento de Candida albicans, C. glabrata e Saccharomyces cerevisiae com TTO altera a permeabilidade e a fluidez da membrana. Essas modificações são produzidas, possivelmente, por alterações induzidas nas propriedades da membrana pela ligação dos terpenos aos ácidos graxos da membrana lipídica, e comprometimento das funções associadas a esta, com acúmulo de trealose no interior da célula (Hammer et al., 2004).

Rev. Bras. Pl. Med., Botucatu, v.13, n.4, p.492-499, 2011. 
Para avaliar a ação do TTO in vitro sobre diferentes cepas de Candida albicans, Hammer et al. (1998) observaram que os fungos foram inibidos numa concentração de $0,25 \%$ de TTO, sugerindo a utilidade no tratamento tópico de infecções provocadas por Candida spp. Oliva et al. (2003) compararam as propriedades antifúngicas do TTO às da fluorocitosina e amfotericina B contra 115 cepas de 14 diferentes fungos, dentre eles $C$. albicans e $C$. glabrata e observaram que a maioria das amostras foi sensível ao TTO quando comparada a outras drogas.

Hammer et al. (2008) concluíram que Enterococcus faecalis coletados de lesões endodônticas possuíram baixa resistência ao TTO. Papadopoulos et al. (2006) relataram atividade semelhante sobre Pseudomonas aeruginosa no tratamento com TTO a 2,0\%.

May et al. (2000) avaliaram a ação do TTO sobre amostras clínicas de Staphylococcus aureus, Klebsiella pneumoniae., Enterococcus faecium, Enterococcus faecalis, Pseudomonas aeruginosa e Stenotrophomonas maltophilia, resistentes a antibióticos. Os autores observaram que em menos de 60 minutos o TTO foi capaz de inativar todas as bactérias, exceto o Staphylococcus aureus.

Hammer et al. (2003) utilizaram o TTO sobre 161 isolados de bactérias orais, determinando 15 diferentes gêneros, dentre eles $A$. actinomycetemcomitans, Actinomyces spp., Fusobacterium spp., Neisseria spp., Porphyromonas endodontalis, Prevotella intermedia, Capnocytophaga spp., Fusobacterium spp., Peptostreptococcus asaccharolyticus, Streptococcus spp. e Veillonella spp. Os autores concluíram que as bactérias bucais são susceptíveis ao TTO, sendo rapidamente inativadas por ele, o que sugere que essa substância pode ser utilizada em produtos odontológicos e na manutenção da higiene oral.

A microbiota bucal está intimamente relacionada ao desenvolvimento da maioria das patologias pulpares. Redução desses microrganismos implica, portanto, na prevenção e controle dessas doenças. O TTO, mesmo em concentrações relativamente baixas, tem apresentado eficácia antimicrobiana contra diversos microrganismos causadores de lesões pulpares, demonstrando que essa substância possui potencial ação terapêutica em pacientes com patologias endodônticas.

\section{CONCLUSÃO}

Pelas atividades antibacteriana, antiviral, antifúngica e antinflamatória o TTO revela-se como boa opção fitoterápica para o tratamento dos problemas bucais. Com base na literatura correlata pode-se inferir que o mecanismo de ação do óleo na atividade antimicrobiana é pela perda da integridade e função da membrana celular e a ação antiinflamatória se dá por meio da redução da produção de citosinas. Para o tratamento de problemas pulpares, principalmente relacionados ao insucesso do tratamento endodôntico, e no controle da cárie o TTO tem demonstrado resultados satisfatórios contra bactérias envolvidas neste processo. $\mathrm{Na}$ doença periodontal além dos benefícios da ação antimicrobiana trabalhos apontam a contribuição da ação antinflamatória na prevenção da gengivite. O que se pode observar diante da literatura exposta é que aplicação do TTO revela-se como alternativa a clorexidina devido aos poucos efeitos colaterais. Entretanto, novos estudos in vivo avaliando a ação sobre microrganismos bucais devem ser realizados, já que este óleo tem demonstrado possibilidade de utilização na odontologia, seja na manutenção química da higiene bucal ou na prevenção e tratamento de patologias orais.

\section{REFERÊNCIA}

ALTMAN, P.M. Australian tea tree oil: a natural antisseptic. Australian Journal of Biotechnology, v.3, n.4, p.247-8, 1989.

ARWEILER, N.B. et al. Clinical and antibacterial effect of tea tree oil - a pilot study. Clinical Oral Investigation, v.4, p.70-3, 2000.

ASCHW ANDEN, C. Herbs for health, but how safe are they? Bulletin of the World Health Organization, v.79, n.7, p.691-2, 2001. Disponível em: <http://www.who.int/ bulletin>. Acesso em: 25 nov. 2009.

BARBOSA, C.A. et al. Evaluation of the antibacterial activities of calcium hydroxide, chlorhexidine and camphorated paramonochlorophenol as intracanal medicament. A clinical and laboratory study. Journal of Endodontics, v.23, n.5, p.227-300, 1997.

BAUMGARTNER, G.; ZEHNDER, M.; PAQUÉ, F. Enterococcus faecalis type strain leakage through root canals filled with Gutta-percha/AH Plus or Resilon/ Epiphany. Journal of Endodontics, v.33, n.1, p.45-7, 2007. BOWEN, W.H. Do we need to be concerned about dental caries in the coming millennium? Critical Reviews in Oral Biology \& Medicine, v.13, n.2, p.126-31, 2002.

BROPHY, J.J. et al. Gas chromatographic quality control for oil of Melaleuca terpinen-4-ol type (Australian tea tree). Journal of Agriculture and Food Chemistry, v.37, p.13305, 1989.

CALIXTO, J.B. Efficacy, safety, quality control, marketing and regulatory guidelines for herbal medicines (phytoterapeutic agents). Brazilian Journal of Medical and Biological Research, v.33, n.2, p.179 -89, 2000.

CARSON, C.F.; MEE, B.J.; RILEY, T.V. Mechanism of action of Melaleuca alternifolia (tea tree) oil on Staphylococcus aureus determined by time-kill, lysis, leakage, and salt tolerance assays and electron microscopy. Antimicrobial Agents and Chemotherapy, v.46, n.6, p.1914-20, 2002.

CARSON, C.F.; HAMMER, K.A.; RILEY, T.V. Melaleuca alternifolia (tea tree) oil: a review of antimicrobial and other medicinal properties. Clinical Microbiology Reviews, v.19, n.1, p.50-62, 2006. 
COX, S.D. et al. The mode of antimicrobial action of the essential oil Melaleuca alternifolia (tea tree oil). Journal of Applied Microbiology, v.88, p.170-5, 2000.

COX, S.D.; MANN, C.M.; MARKHAM, J.L. Interactions between components of the essential oil of Melaleuca alternofilia. Journal of Applied Microbiology, v.91, p.4927, 2001.

DAVEY M.E.; O'TOOLE G.A. Microbial biofilms: from ecology to molecular genetics. Microbiology and Molecular Biology Reviews, v.64, n.4, p.847-67, 2000. DELANY, G.M. et al. The effect of chlorhexidine gluconate irrigation on the root canal flora of freshly extracted necrotic teeth. Oral Surgery, Oral Medicine, Oral Pathology, v.53, n.5, p.518-23, 1982.

DE LORENZO, J.L.; DE LORENZO, A. Microbiologia para o estudante de microbiologia: cariologia - etiopatogenia da cárie dental. São Paulo: Atheneu, 2004. p.87-115.

DITTERICH, R.G. et al. Atividade antimicrobiana in vitro de substâncias naturais presentes nos dentifrícios. Odontologia Clínico-Científica, v.6, n.4, p.303-7, 2007. ELIZABETSKY, E. Pesquisas em plantas medicinais. Ciência e Cultura, v.39, n.8, p.697-702, 1997.

FACHIN, E.V.F.; NUNES, L.S.S.; MENDES, A.F. Alternativas de medicação intracanal em casos de necrose pulpar com lesão periapical. Revista Odonto Ciência, v.21, n.54, p.351-7, 2006.

FARSI, N. Dental caries in relation to salivary factors in Saudi population groups. Journal of Contemporary Dental Practice, v.9, n.3, p.16-23, 2008.

FILOCHE, S.K.; SOMA, K.; SISSONS, C.H. Antimicrobial effects of essential oils in combination with chlorhexidine digluconate. Oral Microbiology and Immunolology, v.20, p.221-5, 2005.

GROPPO, F.C. et al. Antimicrobial activity of garlic, tea tree oil, and chlorhexidine against oral microorganisms. International Dental Journal, v.52, n.6, p.433-7, 2002. GUNSOLLEY, J.C. A meta-analysis of six-month studies of antiplaque and antigingivitis agents. The Journal of the American Dental Association, v.137, p.1649-57, 2006.

GUSTAFSON, J.E. et al. Effects of tea tree oil on Escherichia coli. Letters in Applied Microbiology, v.26, p.194-8, 1998.

HACHMEISTER, D.R. et al. The sealing ability and retention characteristics of mineral trioxide aggregate in a model of apexification. Journal of Endodontics, v.28, n.5, p.386-90, 2002.

HAMMER, K.; CARSON, C.; RILEY, T. In vitro activity of essential oils, in particular Melaleuca alternifolia (tea tree) oil and tea tree oil products, against Candida spp. Journal of Antimicrobial Chemotherapy, v.42, n.5, p.5915, 1998.

HAMMER, K.A.; CARSON, C.F.; RILEY, T.V. In vitro activity of Melaleuca alternifolia (tea tree) oil against dermathophytes and other filamentous fungi. Journal of Antimicrobial Chemotherapy, v.50, p.195-9, 2002.

HAMMER, K.A. et al. Susceptibility of oral bacteria to Melaleuca alternifolia (tea tree) oil in vitro. Oral Microbiology and Immunology, v.18, p.389-92, 2003. HAMMER, K.A.; CARSON, C.F.; RILEY, T.V. Antifungal effects of Melaleuca alternifolia (tea tree) oil and its components on Candida albicans, Candida glabrata and Saccharomyces cerevisiae. Journal of Antimicrobial
Chemotherapy, v.53, p.1081-5, 2004.

HAMMER, K.A.; CARSON, C.F.; RILEY, T.V. Frequencies of resistance to Melaleuca alternifolia (tea tree) oil and rifampicin in Staphylococcus aureus, Staphylococcus epidermidis and Enterococcus faecalis. International Journal of Antimicrobial Agents, v. 32, p.170-3, 2008. HART, P.H. et al. Terpinen-4-ol, the main component of the essential oil of Melaleuca alternifolia (tea tree oil), suppresses inflammatory mediator production by activated human monocytes Inflammation Research, v.49, p.619-26, 2000.

INTERNATIONALORGANISATIONFOR STANDARDISATION. ISO 4730:2004. Oil of Melaleuca, terpinen-4-ol type (tea tree oil). Geneva: International Organisation for Standardisation, 2004. Dísponivel em <http://www.iso.org/ iso/iso_catalogue/catalogue_tc/catalogue_detail. htm?csnumber=37033>. Acesso em: 03 mai. 2011.

JANDOUREK, A.; VAISHAMPAYAN, J.K.; VAZQUEZ, J.A. Efficacy of melaleuca oral solution for the treatment of fluconazole refractory oral candidiasis in AIDS patients. AIDS, v.12, n.9, p.1033-7, 1998.

JOHNS, M.R.; JOHNS, J.E.; RUDOLPH, V. Steam distillation of tea tree (Melaleuca alternifolia) oil. Journal of the Science of Food and Agriculture, v.58, p.49-53, 1992.

KULIK, E.; LENKEIT, K.; MEYER, J. Antimicrobial effects of tea tree oil (Melaleuca alternifolia) on oral microorganisms. Schweizer Monatsschrift Zahnmedizin, v.110, n.11, p.125-30, 2000.

KWIECINSKI, J.; EICK, S.; WÓJCIK, K. Effects of tea tree (Melaleuca alternifolia) oil on Staphylococcus aureus in biofilms and stationary growth phase. International Journal of Antimicrobial Agents, v.33, n.4, p.342-7, 2008. LEONARDO, M.R. Endodontia: tratamento de canais radiculares, princípios técnicos e biológicos. 4.ed. São Paulo: Artes Médicas, 2005.1491p.

MACIEL, M.A.M. et al. Plantas medicinais: a necessidade de estudos multidisciplinares. Química Nova, v.25, n.3, p.429-38, 2002.

MAH, T.C.; O«TOOLE G.A. Mechanisms of biofilms resistance to antimicrobial agents. Trends Microbiology, v.9, n.1, p.34-9, 2001.

MANGIN, C. et al. The comparative sealing ability of hydroxyapatite cement, mineral trioxide aggregate, and super ethoxybenzoic acid as root-end filling materials. Journal of Endodontics, v.29, n.4, p.261-4, 2003.

MAY, J. et al. Time-kill studies of tea tree oils on clinical isolates. Journal of Antimicrobial Chemotherapy, v.45, p.639-43, 2000.

MINAMI, M. et al. The inhibitory effect of essential oils on herpes simplex virus type-1 replication in vitro. Microbiology and Immunology, v.47, p.681-4, 2003.

OLIVA, B. et al. Antimycotic activity of Melaleuca alternifolia essential oil and its major components. Letters in Applied Microbiology, v.37, p.185-7, 2003.

PAPADOPOULOS, C.J. et al. Susceptibility of Pseudomonas to Melaleuca alternifolia (tea tree) oil and components. Journal of Antimicrobial Chemotherapy, v.58, p.449-51, 2006.

PARASKEVAS, S. Randomized controlled clinical trials on agents used for chemical plaque control. International Journal of Dental Hygiene, v.3, n.4, p.16278, 2005. 
PENFOLD, A.R.; GRANT, R. The germicidal values of the principal commercial eucalyptus oils and their pure constituents, with observations on the value of concentrated disinfectants. Journal Royal Society of New South Wales, v.57, p.80-9, 1923.

PENFOLD, A.R.; GRANT, R. The germicidal values of the pure constituents of Australian essential oils, together with those for some essential oil isolates and synthetics. Part II. Journal Royal Society of New South Wales, v.58, p.117-23, 1924.

PENFOLD, A.R.; GRANT, R. The germicidal values of some Australian essential oils and their pure constituents, together with those for some essential oil isolates, and synthetics. Part III. Journal Royal Society of New South Wales, v.59, p.346-9, 1925.

SADR LAHIJANI, M.S. et al. The effect of German chamomile (Marticaria recutita) extract and tea tree (Melaleuca alternifolia) oil used as irrigants on removal of smear layer: a scanning electron microscopy study. International Endodontic Journal, v.39, p.190-5, 2006. SEDGLEY, C.M.; LENNAN, S.L.; APPELBE, O.K. Survival of Enterococcus faecalis in root canals ex vivo. International Endodontic Journal, v.38, n.10, p.735-42, 2005. SELWITZ, R.H.; ISMAIL, A.I.; PITTS, N.B. Dental caries. Lancet, v.369, p.51-9, 2007.

SHIPPER, G. et al. An evaluation of microbial leakage in roots filled with a thermoplastic synthetic polymer-based root canal filling material (Resilon). Journal of Endodontics, v.30, n.5, p.342-7, 2004.

SOUKOULIS, S.; HIRSCH, R. The effects of a tea tree oilcontaining gel on plaque and chronic gingivitis. Australian Dental Journal, v.49, n.2, p.78-83, 2004.

SPRATT, D.A.; PRATTEN, J. Biofilms and the oral cavity. Reviews in Environmental Science and Biotechnology, v.2, p.109-20, 2003.

SYED, T.A. et al. Treatment of toenail onychomycosis with $2 \%$ butenafine and $5 \%$ Melaleuca alternifolia (tea tree) oil in cream. Tropical Medicine \& International Health, v.4, p.284-7, 1999.

TAKARADA, K. et al. A comparasion of the antibacterial efficacies of essential oils agaist oral pathogens. Oral Microbiology and Immunology, v.19, p.61-4, 2004.

TRABOULSI, R.S.; MUKHERJEE, P.K.; GHANNOUMA, M.A. In vitro activity of inexpensive topical alternatives against Candida spp. isolated from the oral cavity of HIVinfected patients. International Journal of Antimicrobial Agents, v.31, p.272-6, 2008.

TWETMAN, S. Antimicrobials in future caries control? A review with special reference to chlorhexidine treatment. Caries Research, v.38, n.3, p.223-9, 2004.

VALERA, M.C.; REGO, J.M.; JORGE, A.O.C. Effect of sodium hypoclorite and five intracanal medications on Candida albicans in root canals. Journal of Endodontics, v.27, n.6, p.401-3, 2001.

VAN VUUREN, S.F.; SULIMAN, S.; VILJOEN, A.M. The antimicrobial activity of four commercial essential oils in combination with conventional antimicrobials. Letters in Applied Microbiology, v.48, n.4, p.440-6, 2009.

VILLENA, R.S.; CURY, J.A. Flúor - Aplicação Sistêmica. In: CORREAA, M.S.N. Odontopediatria na primeira infância. São Paulo: Santos, 1998. p.291-314.

WILKINSON, J.M.; CAVANAGH, H.M.A. Antibacterial activity of essential oils from Australian native plants. Phytotherapy Research, v.19, p.643-6, 2005.

WILLIANS, L.P. Antimicrobial activity of oil lelaleuca (tea tree oil). Its potential use in cosmetics and toiletries. Cosmetics Aerosols Toil Australia, v.4, n.4, p.12-22, 1990. 